\title{
DETERMINATION OF THE CAUSES FOR CRACK INITIATION IN STRUCTURAL ELEMENTS OF THE TOWER OF NEW VENTILATION PIPE AT CHERNOBYL NPP
}

\author{
V.M. TOROP ${ }^{1}$, E.F. GARF ${ }^{1}$, A.V. YAKIMKIN ${ }^{1}$ and E.E. GOPKALO ${ }^{2}$ \\ ${ }^{1}$ E.O. Paton Electric Welding Institute, NASU \\ 11 Bozhenko Str., 03680, Kiev, Ukraine. E-mail: office@paton.kiev.ua \\ ${ }^{2}$ G.S. Pisarenko Institute for Problems of Strength, NASU \\ 2 Timiryazevskaya Str., 01014, Kiev, Ukraine. E-mail: office@ipp.kiev.ua
}

\begin{abstract}
Analysis of design and service documentation, as well as correspondence of actual loads and service modes of the new ventilation pipe (NVP) to this documentation requirements, has been performed. Results of non-destructive testing of base metal and welded connections of structural elements on the NVP at ChNPP have been analyzed. Cracks in tower nodes of ChNPP NVP are of systematic nature. They formed in the zones of node welded connections of tower three upper tiers, in which the lattice elements are made of pipes of $193.7 \times 6 \mathrm{~mm}$ cross-section. At present cracks were detected in 17 nodes of slotted gusset of the post and in 17 nodes of brace attachment to straining sill. Templates were cut out, which are crack-containing fragments of gussets, i.e. structural elements of ChNPP NVP, samples were prepared and experimental investigations of the composition, microhardness, mechanical properties and structure of base metal, HAZ and weld metal have been performed. Causes for and mechanisms of cracking in structural elements of the NVP have been determined during performance of materials science investigations in two cut-out templates. Fractographic studies revealed the fatigue nature of surface crack initiation and propagation in gussets. Aerodynamic and strength analyses of the construction and its individual elements have convincingly demonstrated that the cause of cracking are resonance vibrations of braces in the upper three sections of the tower, directed out of face plane and inducing alternating bending stresses in the nodes. Vibration frequencies and forces transferred to the nodes have been determined. Stress fields caused by periodic forces in the braces, confirm the existence of the zone of fracture initiation and development, and maximum stress levels greatly exceed welded connection fatigue limits. A conclusion was made that the tower was designed using out-dated design concepts for nodes, characterized by numerous zones of high stress concentration, low fatigue and corrosion resistance. 12 Ref., 1 Table, 20 Figures.
\end{abstract}

Keywords: welded connections, welded nodes, fa tigue, resonance, fatigue life, fractography, metallographic investigations, fatigue crack, strength analysis, new ventilation pipe, Chernobyl NPP

Analysis of design documentation showed that construction of new ventilation pipe (NVP) was performed over premise 7001 of block $\mathrm{C}$ of the main building of second stage of Chernobyl NPP (ChNPP) between D1-Zh/36-37 axes. The main building of ChNPP second stage is a complex construction, including 3rd power generating unit, destroyed 4th power generating unit ( $\ll \mathrm{Uk}-$ ritie» structure) and block $\mathrm{C}$ common for both power generating units. The currently operating ventilation pipe VT-2 is located between axes $\mathrm{I}-\mathrm{N} / 36-40$.

NVP is a tower in the form of a load-carrying steel frame accommodating a gas flue of $6 \mathrm{~m} \mathrm{di-}$ ameter. Load-carrying frame of NVP tower is a tetrahedral latticed structure of $8.05 \times 8.05 \mathrm{~m}$ dimensions (in the axes) in plan view and $50 \mathrm{~m}$ height. Inside the tower horizontal diaphragms with $7.2 \mathrm{~m}$ step are envisaged which are combined with foot platforms. Vertical trestle ladders provide access to the platforms. NVP tower is resting against a metal support contour at $71.65 \mathrm{~m}$ mark. Tower posts, main ties and lattices between the posts are made of cylindrical electric-welded pipes.

Gas flue of $6 \mathrm{~m}$ diameter with four vertical stiffeners is supported by a metal contour at $71.65 \mathrm{~m}$ mark. Top mark of the gas flue is $125 \mathrm{~m}$. Gas flue is tied every $7.2 \mathrm{~m}$ along its height to tower diaphragms in the horizontal direction. Gas flue butts are joined by flanged connections using bolts. Dismantling of ceramsite concrete plates of the roofing at $71 \mathrm{~m}$ mark on $\mathrm{D} 1-\mathrm{Zh} / 36-37$ axes is envisaged for connection of the gas flue to premise 7001 of block C.

Metal support contour is a system of beams, attached by horizontal ties. NVP tower posts are fixed on two main beams of support contour, 


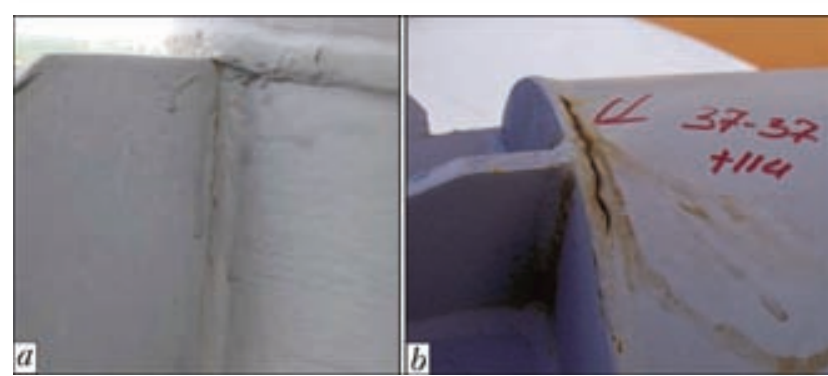

Figure 1. Cases of crack propagation in tower brace nodes (for $a$ and $b$ see the text)

located along axes D1 and Zh. Support contour main beams are attached to the existing concrete structures of block $\mathrm{C}$ in four points at $70.7 \mathrm{~m}$ mark along axes D1-Zh/36-37. Supporting nodes of main beam fastening are designed to accommodate vertical (including tearing) and horizontal loads from NVP.

Braces of NVP tower lower tiers are pipes of $245 \mathrm{~mm}$ diameter with $8 \mathrm{~mm}$ wall thickness for BC1 braces. For BC2 braces $1219 \times 6 \mathrm{~mm}$ pipe was specified. BC3 braces, mounted at 100.36$121.96 \mathrm{~m}$ mark, are made from $193.7 \times 6 \mathrm{~mm}$ pipe. Flexibility $\lambda$ of BC3 braces is 170 . Flexibility of BC1 and BC2 braces is 130 and 150, respectively, negative influence of vibrations being less pronounced for these elements. It should be also taken into account that in the lower tiers gussets are made from rolled sheets of greater thickness than gussets in fastening nodes of BC3 braces, the thickness of which is $12 \mathrm{~mm}$. According to the data given in [1], a potentially hazardous area of development of self-excited oscillations of round steel rods in latticed structures are elements with $\lambda$ from 100 up to 350 .

Examination of NVP tower node connections performed by PWI specialists and the thus revealed crack-like defects [2], materials science investigations of metal in the cracking zone and detailed analysis of fracture surface [3], enabled applying a weighted and substantiated approach to establishing the causes for crack initiation in NVP nodes.

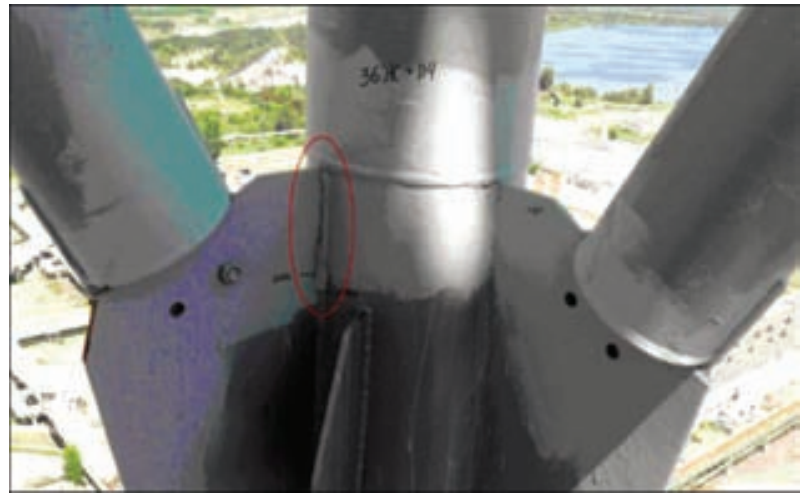

Figure 2. Crack-like defects in the node of brace abutment to tower post

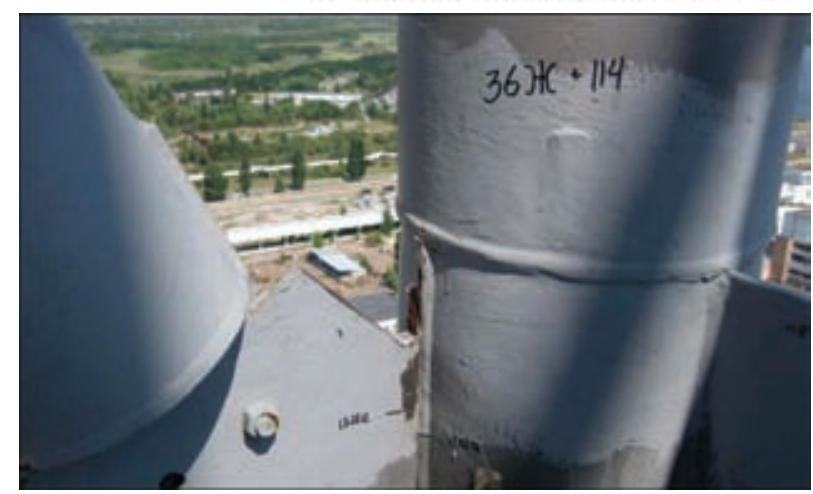

Figure 3. Node of brace abutment to tower post after cutting out template \#1

Examination of metal structures of NVP loadcarrying frame on the level of upper tiers of tower frame at 114.92, 107.72 and $100.52 \mathrm{~m}$ marks [2] revealed the following drawbacks:

- absence of assembling bolts, because of misalignment of holes in connecting gussets (caused by violation of geometrical accuracy during frame assembly);

- presence of cracks in the upper part of vertical gussets of posts in points of brace abutment.

Note the fact that location of detected cracks is of systematic nature. All the cracks were found in three upper sections of the tower. A common feature for these sections is the fact that the lattice elements are made of cylindrical pipes of $193.7 \times 6 \mathrm{~mm}$ cross-section, and gussets have $12 \mathrm{~mm}$ wall thickness. In these sections cracks were found in 17 out of 24 nodes connecting the brace to slotted gusset of tower post, and out of the 24 nodes connecting the brace to straining sill cracks were detected in 17 of them (Figure 1). It should be noted that specialists conducted examination under the conditions of a high radiation background and were limited in time. Therefore, there is strong probability that not all the crack were detected.

Cracks are of different length. They initiate from the edge in the upper part of node gusset

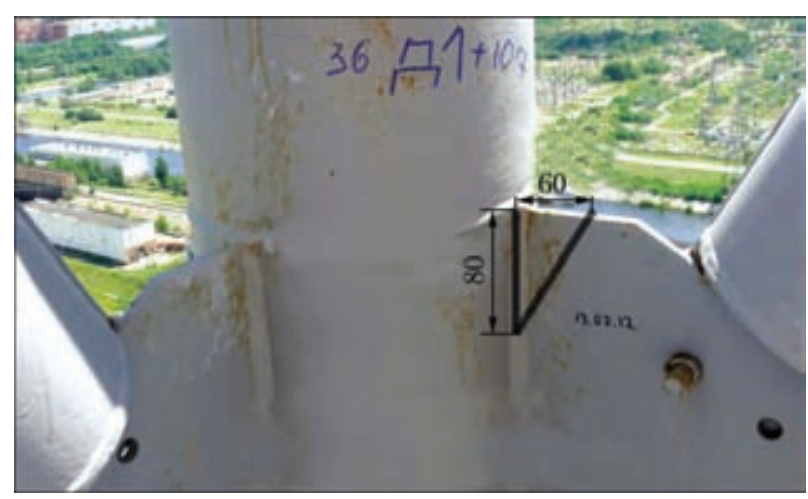

Figure 4. Schematic of cutting out template \#2 (cracked fragment of gusset with complete weld structure up to the end of detected crack) 
SCIENTIFIC AND TECHNICAL

Metal composition, wt.\%

\begin{tabular}{|c|c|c|c|c|c|c|c|c|c|c|c|}
\hline Data source & $\mathrm{C}$ & $\mathrm{Si}$ & $\mathrm{Mn}$ & $\mathrm{P}$ & S & $\mathrm{Cr}$ & Mo & $\mathrm{Ni}$ & $\mathrm{Cu}$ & $\mathrm{Al}$ & Co \\
\hline $\begin{array}{l}\text { Q2 ION } \\
\text { spectrometer }\end{array}$ & $\begin{array}{c}0.146- \\
0.158 \\
\end{array}$ & $\begin{array}{c}0.134- \\
0.170 \\
\end{array}$ & $\begin{array}{c}0.60- \\
0.62 \\
\end{array}$ & $<0.03$ & $<0.01$ & $\begin{array}{c}0.026- \\
0.032 \\
\end{array}$ & $<0.01$ & $<0.01$ & 0.005 & $<0.047$ & 0.016 \\
\hline $\begin{array}{l}\text { GOST 27772- } \\
88(\mathrm{~S} 255)\end{array}$ & $\leq 0.22$ & $\begin{array}{c}0.15^{-} \\
0.30 \\
\end{array}$ & $\leq 0.65$ & $\leq 0.04$ & $\leq 0.05$ & $\leq 0.30$ & - & $\leq 0.30$ & $\leq 0.30$ & - & - \\
\hline $\begin{array}{l}\text { GOST 380-94 } \\
\text { (St3Gps) } \\
\text { (semikilled) }\end{array}$ & $\begin{array}{c}0.14- \\
0.22\end{array}$ & $\leq 0.15$ & $0.8-1.1$ & $\leq 0.04$ & $\leq 0.05$ & $\leq 0.30$ & - & $\leq 0.30$ & $\leq 0.30$ & - & - \\
\hline $\begin{array}{l}\text { GOST 380-94 } \\
\text { (St3Gsp) } \\
\text { (killed) }\end{array}$ & $\begin{array}{c}0.14- \\
0.20\end{array}$ & $\begin{array}{c}0.15- \\
0.30\end{array}$ & $0.8-1.1$ & $\leq 0.04$ & $\leq 0.05$ & $\leq 0.30$ & - & $\leq 0.30$ & $\leq 0.30$ & - & - \\
\hline
\end{tabular}

(node of lattice elements abutment to tower post) and develop downwards along the gusset and indepth (Figure 1, $a$ ). In the node of braces abutment to the straining sill cracks are found in the connection of the stiffener and brace pipe through a thin plug sealing the brace inner space (Figure 1, $b$ ).

Another specific feature: in tower post nodes cracks form from two sides of the gusset, propagating in-depth and moving towards each other. Cracks propagate along the boundary of transition from fillet weld joining the tower post to slotted gusset, to gusset base metal. In those cases, when fillet welds from one and the other side of the gusset have different legs, cracks propagate with the appropriate shifting.

The characteristic appearance of crack-like defects detected by NDT is given in Figure 2 .

Metallographic and fractographic investigations were performed to establish the causes for initiation of crack-like defects in NVP metal structures. Templates of gussets with anticipated cracks were cut out at $36 \mathrm{Zh}+114$ (cutting out area is shown in Figure 3) - template \#1 and $36 \mathrm{D} 1+107$ marks (cutting out schematic is shown in Figure 4) - template \#2, respectively.
According to documentation, gusset metal (12 mm sheet) is low-carbon structural steel of S255 class.

To identify the gusset material, composition of gusset base metal was analyzed (optico-emission spectrometer Q2 ION based on CCD detectors) and the results are given in the Table.

By chemical composition (manganese content) the specified gusset metal did not meet the requirements of GOST 380-94 to steels of St3Gps and St3Gsp grades (S255 steel analogs), although it meets the requirements for steel S255, according to GOST 27772-88 (see the Table). In addition, mechanical testing was performed for accurate identification of gusset steel grade, the results of which confirmed their correspondence to steel S255 (according to the requirements of GOST 1497-84). Mechanical testing of standard smooth samples conducted at $20^{\circ} \mathrm{C}$ showed mean values of tensile strength of $453 \mathrm{MPa}$, yield point of $285 \mathrm{MPa}$, relative elongation of 31.7 and reduction in area of 54.4.

To analyze (establish) the causes for and mechanisms of formation of crack-like defects in the structure, comprehensive investigations of

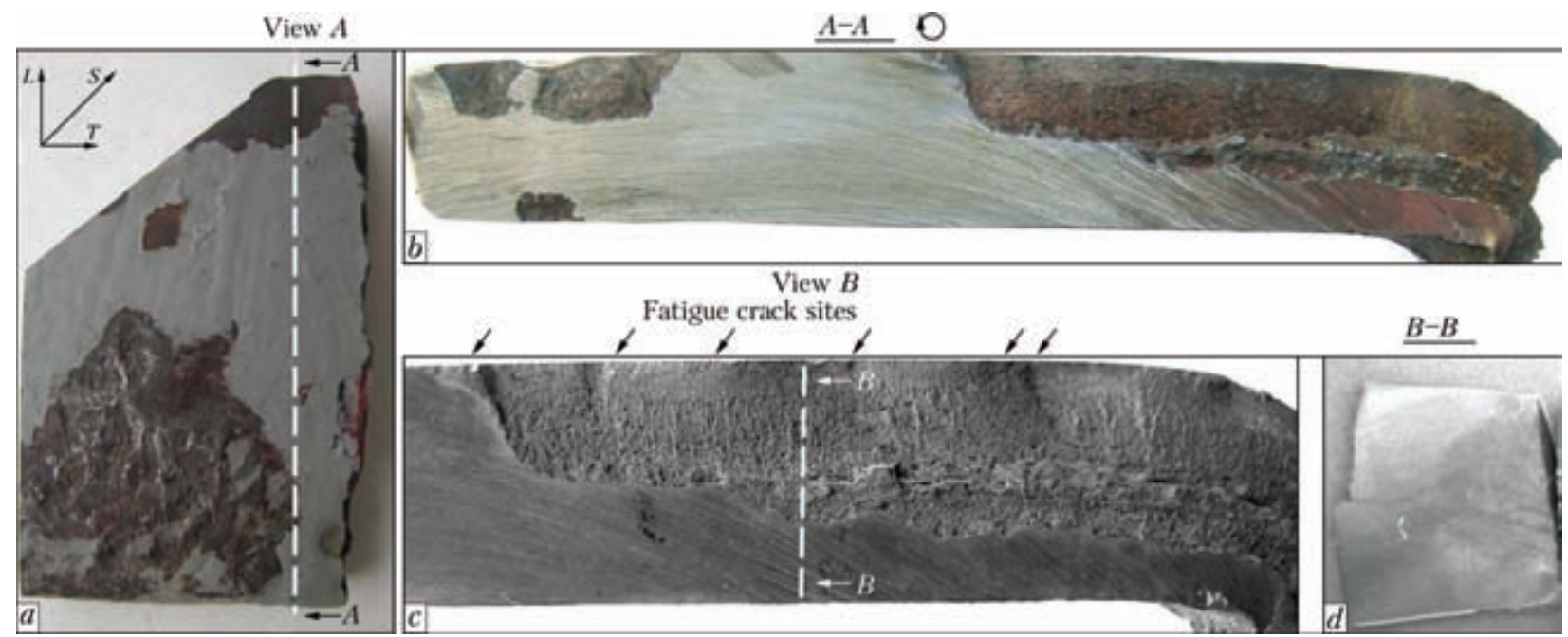

Figure 5. Template \#1 with open crack: $a$ - template appearance; $b, c$ - fragment of gusset in crack plane $L-S$ before and after crack surface cleaning to remove corrosion products, respectively (gusset section $A-A$ ); $d-$ microsection plane in plane $S-T$ (gusset section $B-B$ ) 
the presented templates in the vicinity of welded connections, including visual examination, metallographic analysis in optical inverted microscope AXIOVERT 40-MAT and fractographic analysis in an upgraded scanning electron microscope REM-100U were performed.

Samples for metallographic examination were cut out in the plane of $S-T$ cross-section of the gussets normal to sheet rolling plane $L-T$ (where $L$ is the rolling direction coinciding with longitudinal direction of the weld; $T$ is the direction in the rolling plane; $S$ is the direction normal to rolling plane).

Template \#1 in as-delivered condition along one of the sides was cut out in crack plane $L-S$ along the fillet weld normal to gusset sheet rolling plane $L-T$ (Figure 5). Crack surface in cut plane is covered by corrosion products, and that is why ultrasonic cleaning of the surfaces from corrosion products was performed in ultrasonic disperser UZDH before fractographic investigation, using $2 \%$ alcohol solution of oxalic acid and then pure ethyl alcohol. Figure 5, $c$ shows a gusset fragment in crack plane $L-S$ after removal of the protective layer from the sheet outer surfaces and crack surface cleaning from corrosion products.

Fractographic investigations of opened crack surfaces in the cut plane revealed crack initiation sites and propagation mechanisms in welded connection of template \#1, although the weld zone proper is not in the template. Proceeding from fractographic studies cracks are identified as fatigue, initiating on surface defects. Fatigue crack sites are marked by arrows in Figure 5, c. Figure 6 shows a characteristic fragment of fractogram of a gusset with fatigue crack (with initiation site, characteristic fracture relief and traces of fatigue crack front arresting). The main crack formed as a result of coalescence of several fatigue cracks, which initiated from different sites on the gusset outer surface and grew in-depth of the sample to 5 to $6 \mathrm{~mm}$ (approximately to half of gusset sheet thickness). In some fracture areas coarse globular non-metallic inclusions are observed, which are commensurate with ferrite of gusset base metal (crack might have crossed the fusion zone in such areas).

As shown by metallographic investigations of crack profile fragments in plane $S-T$ of one of the cross-sections, the crack initiated on gusset outer surface in HAZ coarse-grain zone.

Here fine secondary delamination microcracks several micrometers long oriented along the rolling texture are observed along the primary crack profile line (in welded connection cross-section), and at about $5 \mathrm{~mm}$ distance from the outer surface already an extended secondary delamination crack of about 450-500 $\mu \mathrm{m}$ length formed ( $\mathrm{Fi}^{-}$

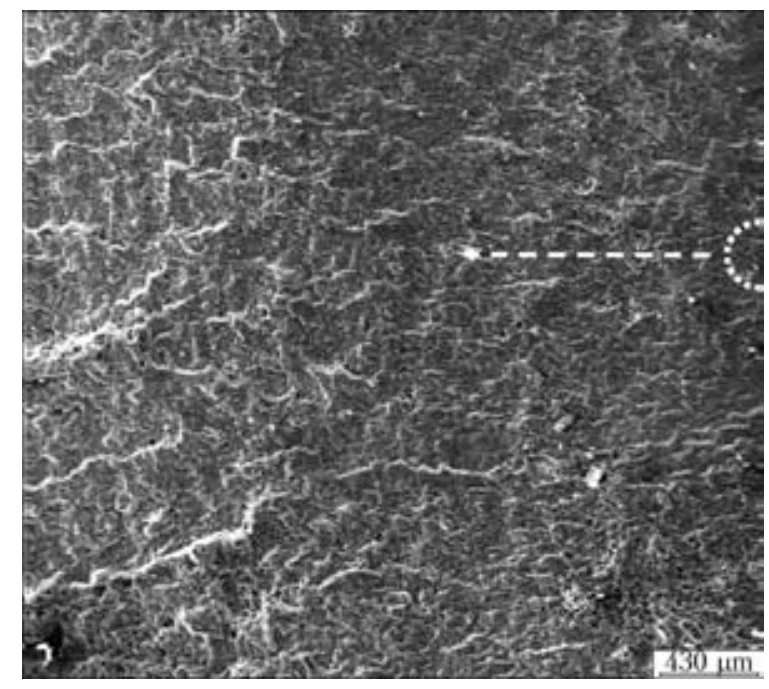

Figure 6. Fractogram of gusset (template \#1) in plane $L-S$ with fatigue crack (white contour marks fatigue crack site, arrow shows direction of crack front)

gure 7), which was also due to rolling texture. It propagated along extended pearlite colonies and sulphide inclusions, which are observed in the studied template section (see enlarged fragment in Figure 7).

Figure 8 shows a fragment of template \#2 of a welded connection in plane $S-T$ after etching in $4 \%$ solution of nitric acid in ethyl alcohol with marking of zones of weld, HAZ and BM.

Microstructure of gusset BM is a ferrite-pearlite mixture of polyhedral ferrite with a small amount of fine-grained pearlite. With general diversity of ferrite grains $(14-30 \mu \mathrm{m})$ average size of ferrite grains was $20-25 \mu \mathrm{m}$. A high density of finely dispersed carbide was observed in ferrite grains. Gusset BM is characterized by striated rolled pattern. Measurement of microhardness at $0.5 \mathrm{~N}$ load was conducted in T-Durascan-20 microhardness meter according to GOST 9450-84. Microhardness of ferrite grains in BM, depending on density of finely dispersed carbide in them,

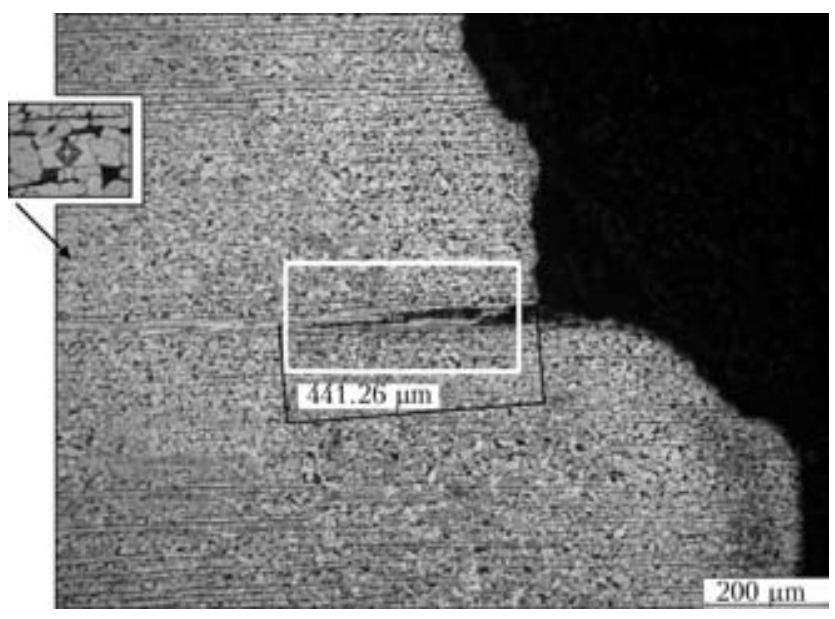

Figure 7. Fractogram of secondary crack of gusset delamination 


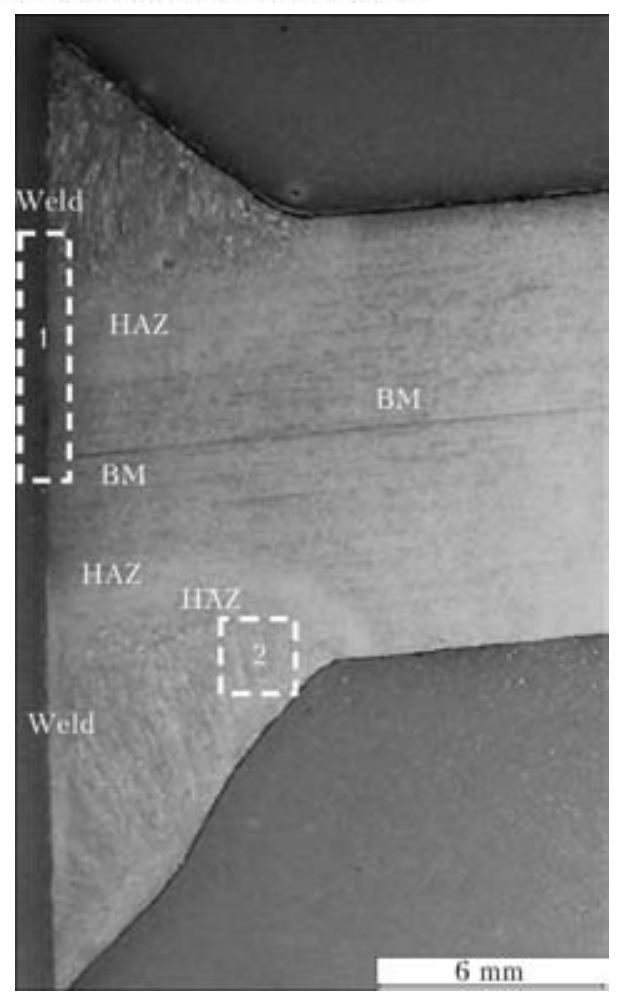

Figure 8. Fragment of welded joint microsection (template $\# 2)$ in plane $S-T$

varies in the range of $H V$ 1500-1670, and that of pearlite is of about $H V$ 1770-1930 MPa.

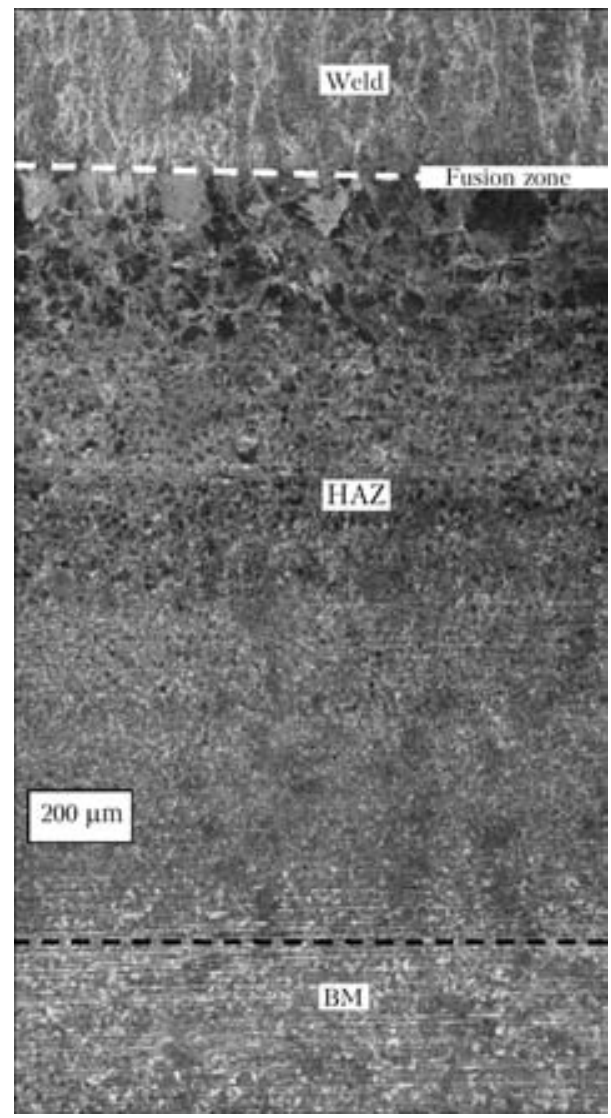

Figure 9. Panoramic view of microstructure fragment (template \#2) of section 1 in Figure 8

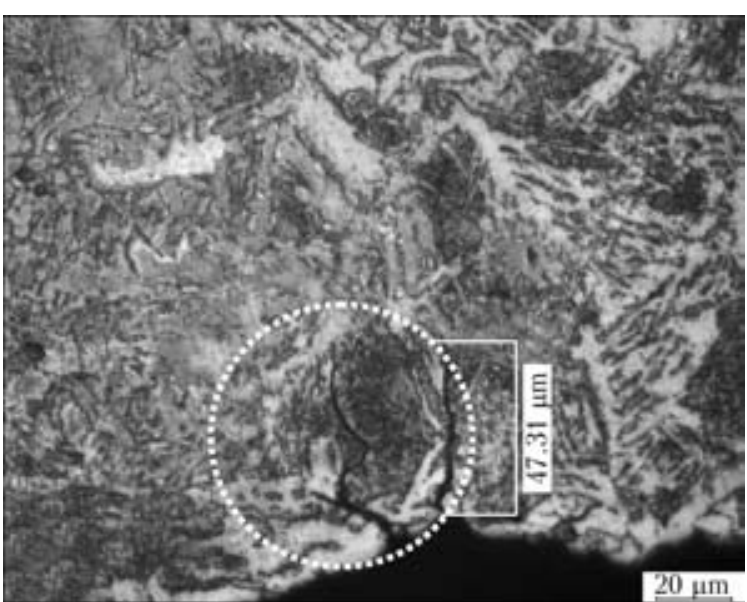

Figure 10. Microstructure fragment (template \#2) of section 2 in Figure 8 (dot contour marks microcrack area)

In weld zones no defects in the form of microcracks were found. Weld metal microstructure are columnar crystallites with characteristic directed orientation, indicating direction of solidification from the liquid state. Microhardness of columnar crystallites at $1 \mathrm{~N}$ load was of about $H V 2350 \mathrm{MPa}$ on average.

Panoramic view of a fragment of microstructure in zone 1 (see Figure 8) including the structure of the weld, fusion zone, HAZ and gusset $\mathrm{BM}$ is shown in Figure 9. Overheating zone ( «coarse-grain» zone of about 400-600 $\mu \mathrm{m}$ width) is located near the fusion zone in the HAZ. Its grains are characterized by Widmanstaetten structure with lower mechanical properties. Total HAZ width is within $900-2900 \mu \mathrm{m}$.

Detailed investigation of welded connection microstructure in plane $S-T$ of the microsection near the fusion zone revealed two microcracks of $50-60 \mu \mathrm{m}$ size, initiating on the stress raiser in the form of a defect of template outer surface in the area of HAZ coarse grain (Figure 10). Such fine cracks could hardly be detected by other methods, in view of outer surface roughness, and presence of a layer of scale on it. As shown by investigations, thickness of scale layer on gusset surface reaches $30 \mu \mathrm{m}$ in individual locations,

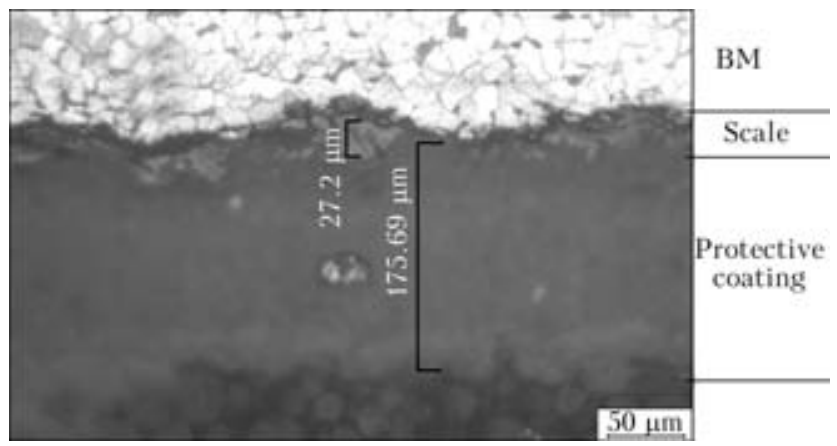

Figure 11. Fragment of gusset section with scale and protective coating 
and protective coating thickness is $180 \mu \mathrm{m}(\mathrm{Fi}-$ gure 11).

The above data lead to the conclusion that forces in tower braces are responsible for crack initiation and propagation, as exactly the forces in braces in slotted gussets induce stresses, the nature of distribution of which is in complete agreement with the regularities of crack propagation in tower nodes. However, if we assume that only longitudinal forces are found in tower braces, caused by loads applied during the construction service, then stresses induced by them could not in any way lead to detected damage. Initiation and propagation of cracks from two sides of slotted gussets in tower post nodes and crack formation in the nodes of brace connection to the sill, are indicative of the fact that bending stresses are present in these nodes, which can be caused only by the respective forces in braces.

The fact that in the post gussets cracks initiate and propagate along the boundary of transition from welded joint to base metal, and across metal thickness cracks develop normal to its surface, as well as the difference in crack dimensions in different nodes, are indicative of their fatigue origin. This is convincingly confirmed also by the above-described fractographic investigations, in particular, characteristic fracture surface, presence of crack initiation sites, striations characteristic for crack arresting and initiation (see Figures 5 and 6 ).

Therefore, it terms of welded structure strength there is no doubt that the cracks detected in NVP tower nodes are of fatigue nature and are caused by bending stresses, developing at brace vibration out of tower panel plane. Here periodical forces should arise in the crack zone, causing cyclic stresses sufficient for fatigue crack initiation and propagation. Note that it took less than seven months for the cracks to initiate. That is why, crack formation is possible only in the case if the braces start resonating at certain real wind velocities, and the forces and stresses arising here are capable of causing fatigue fractures in the nodes. Another argument in favour of exactly this cause for damage initiation consists in that brace flexibility is the highest in the three upper tiers of the tower. This also accounts for the fact that cracks were detected exactly in these tiers.

On the other hand, we cannot ignore the opinion on the considered problem expressed by specialists of Bechtel Company, USA, who conducted an independent investigation of NVP elements, containing defects [4]. Two specialists in the field of metallurgy and one specialist on welding technology and NDT participated in investi- gations. At the very beginning of their investigations the authors conclude that the «design is ruled out as a possible cause for defect initiation», substantiating it by the fact that the construction was not exposed to design loads since the moment building was over and up to crack detection. By doing that the investigation authors essentially limited the area of searching for the causes for crack initiation in the tower nodes. If the design factor is eliminated a priori, then simply nothing else, but the technological factor, is left to account for the fracture causes.

During investigation it was established that steel of S345 class was used in $12 \mathrm{~mm}$ gusset cut out together with the fillet weld from a node at $100 \mathrm{~m}$ mark, while the project envisaged class S255 steel. It is not of any fundamental importance in itself, but higher hardness ( $H V$ up to $3985 \mathrm{MPa}$ ) and a «small amount of martensite in the near-weld zone» were found in the weld and HAZ that may be indicative of an increased rate of welded joint cooling. The above was used as a basis to make the conclusion that «the mot probable cause of crack initiation is hydrogen cracking». The authors realize that increased hardness and martensite presence in the HAZ proper cannot cause cold cracks, so an assumption is made that in the manufacturing plant welding was performed under the conditions of «rain, snow, high humidity or strong wind».

Certainly, it is difficult to accept such a conclusion, although the authors do express it cautiously enough. First, the conditions of welding must have been the same along the entire length of the gusset, and cracks in all the cases are found in those points where the force is transferred from the brace, i.e. in the gusset upper part. Secondly, cold cracks are located predominantly in the HAZ, i.e. along the weld fusion zone, and the considered cracks propagate normal to gusset surface, and, finally, none of the studies revealed presence of cold cracks either in the weld, or in the HAZ. In addition, cracks are found both in gussets made from steel of S345 class, and in gussets made from steel S255, although the authors of the analyzed investigation are convinced that no cracks will be present in steel of S255 class.

To determine the conditions of development of brace resonance vibrations, their frequency characteristics, as well as levels of induced cyclic stresses, a complex analysis of braces for wind load was performed, which was treated as disturbing factor, causing resonance vibrations.

Note that the above data, based on the results of examination and fractographic investigations of fracture surface, are quite sufficient to make 


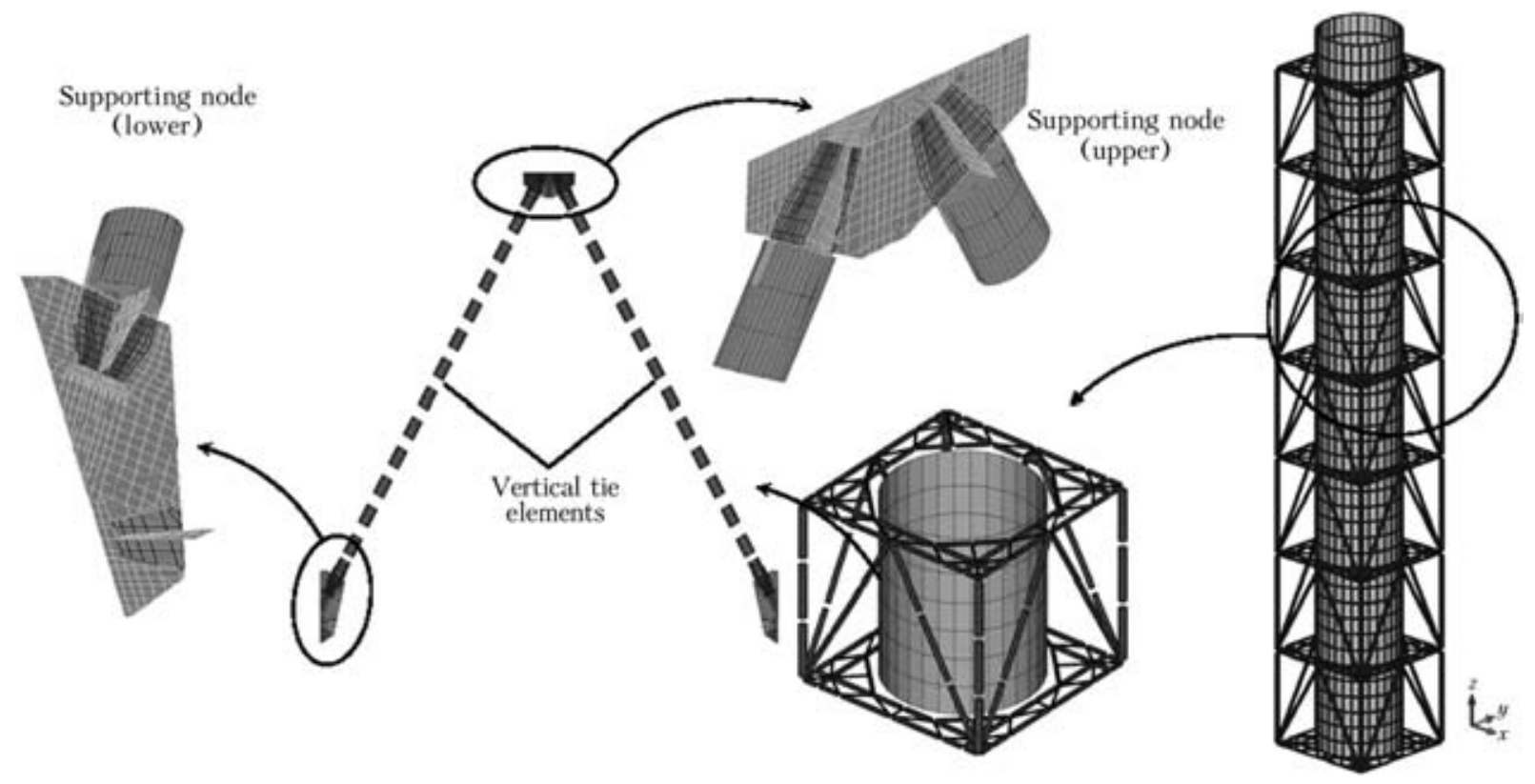

Figure 12. NVP FEM models

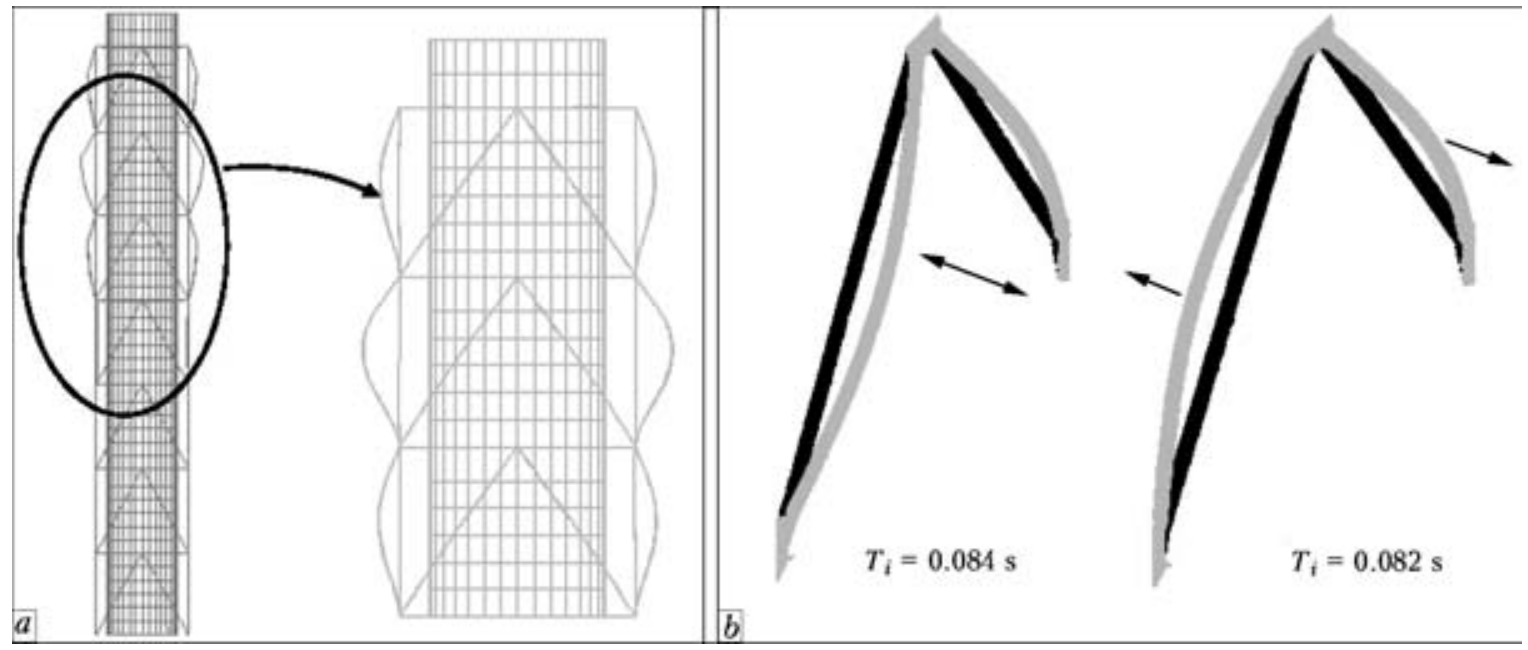

Figure 13. Forms of natural vibrations (for $a$ and $b$ see the text)

an unambiguous conclusion about the causes for and nature of initiating cracks.

Calculation given below is just a tool, explaining facts quite obvious for specialists, and it can only be regarded as an independent criterion for taking a critical decision, if one is absolutely sure of its correctness. Authors have to draw attention to this fact as insufficiently cor-

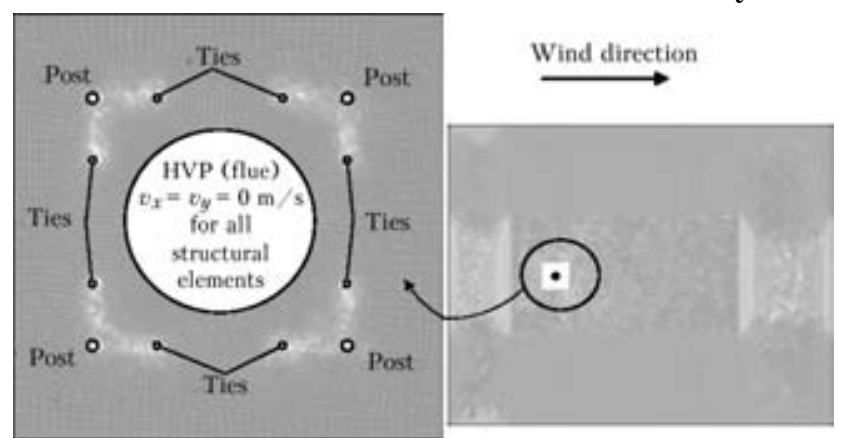

Figure 14. Aerodynamic model: general view, loads and boundary conditions $\left(v_{x}=12, v_{y}=0 \mathrm{~m} / \mathrm{s}, P=0 \mathrm{~Pa}\right)$ rectly performed calculation leads to erroneous conclusions.

Main stages and sequence of calculation performance. According to the above-given results of metallographic analysis of gusset fragments it is established that the mechanism, which caused crack initiation and propagation, is of fatigue nature.

Analysis of initial data allowed ignoring some kinds of loads (taken into account in NVP design), namely: class 3 tornado, 5 and 6 point earthquake, snow load and temperature impact. As during NVP operation (since the moment of its commissioning and up to crack initiation in gussets) some of the above loads were completely absent, others did not exceed their design values, while their repeatability was insignificant, they could not cause cracking.

Considering that for high-rise constructions it is exactly the wind load as a dynamic disturbing 


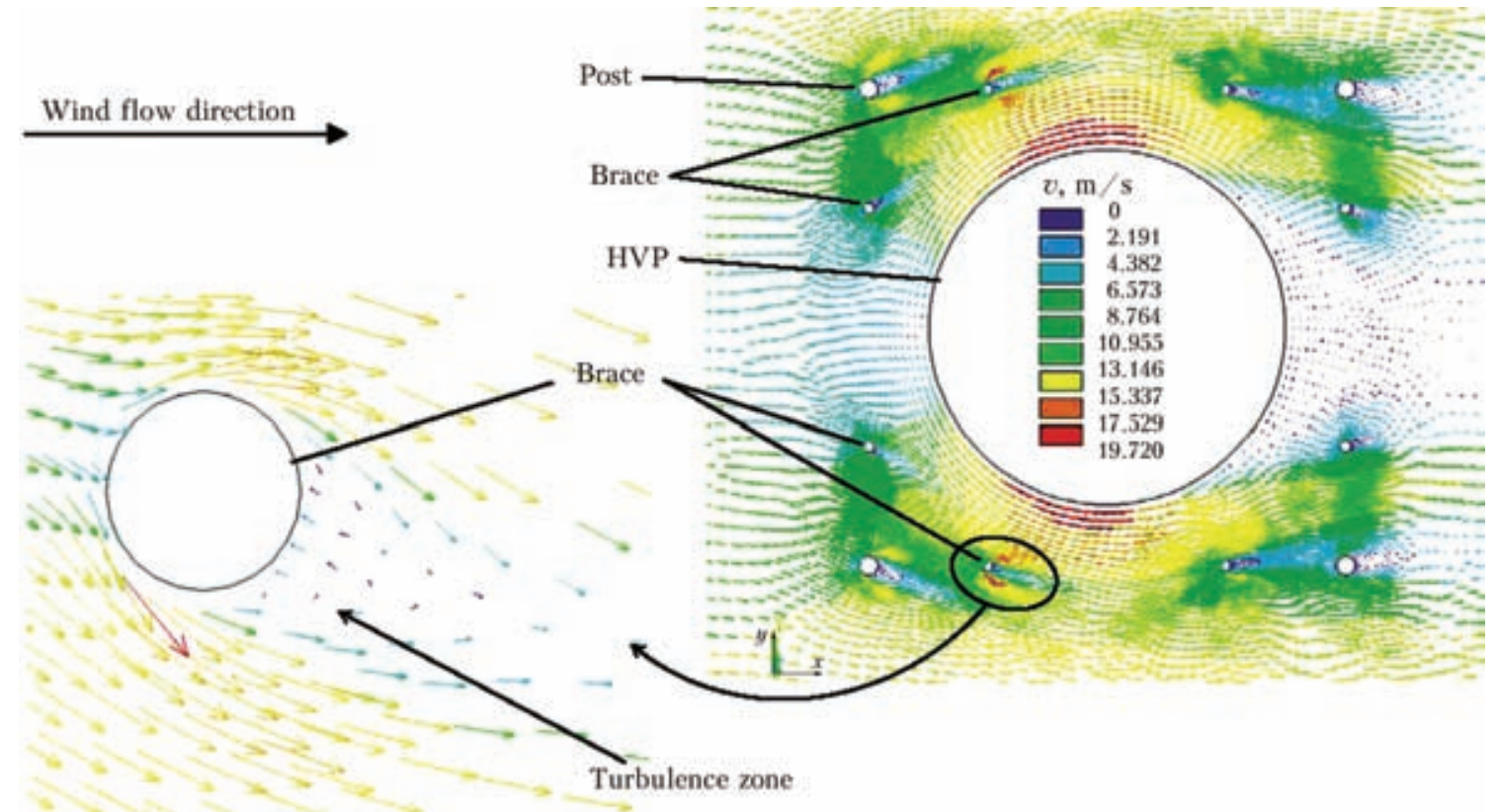

Figure 15. Direction of wind flow velocity vectors

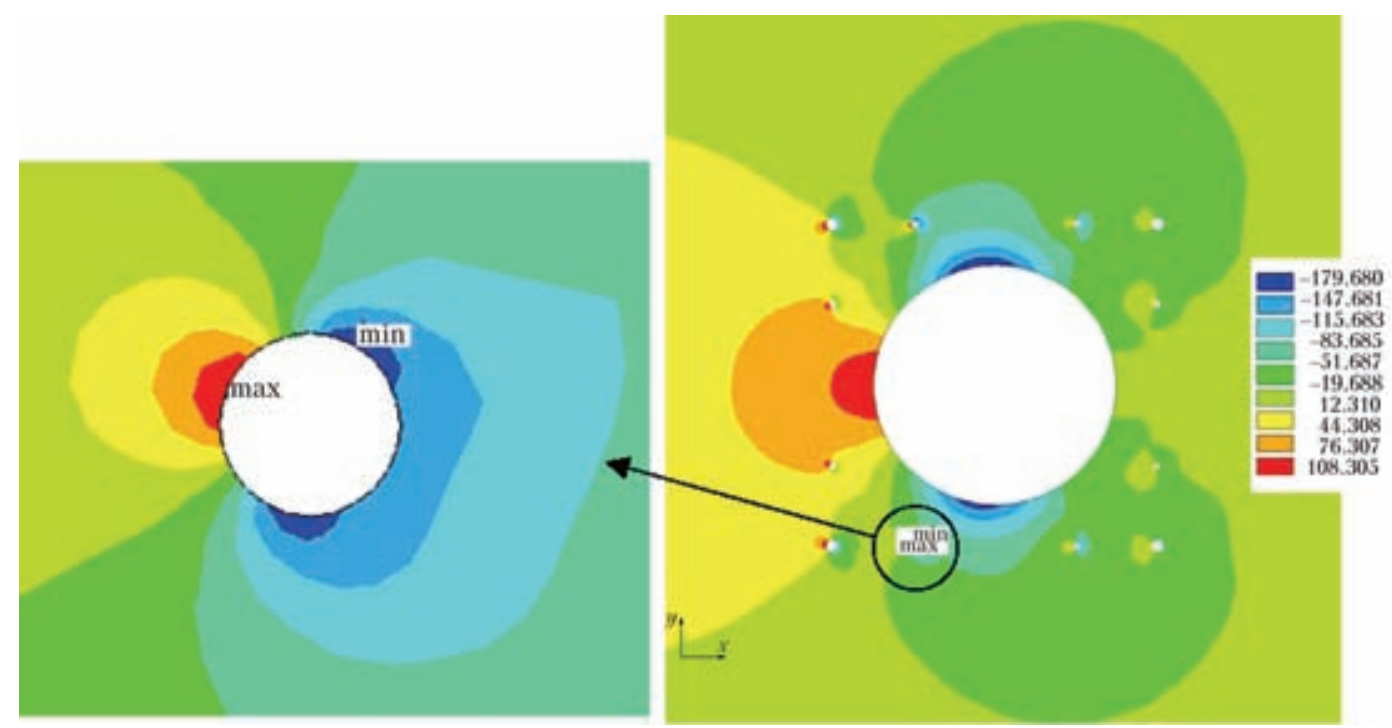

Figure 16. Wind pressure isofields

factor that is the main one, the influence of wind flow on stress-strain state of NVP and its individual structural elements is analyzed.

Problem was solved in several stages, using aerodynamic and strength numerical models. This is due to a rather complicated nature of interaction of the wind flow and building structures - crosseffect of adjacent structural elements on distribution of velocity and force of winds, etc.

As a result of calculation of shell-rod 3D FEM models (Figure 12) forms and periods of system natural vibrations were determined.

Detailed analysis of the derived results revealed that in a number of cases the forms of NVP natural vibrations are created by group deformation of braces of three upper sections (Figure $13, a$ ). Brace vibrations are characterized by their buckling out of panel plane. Charac-

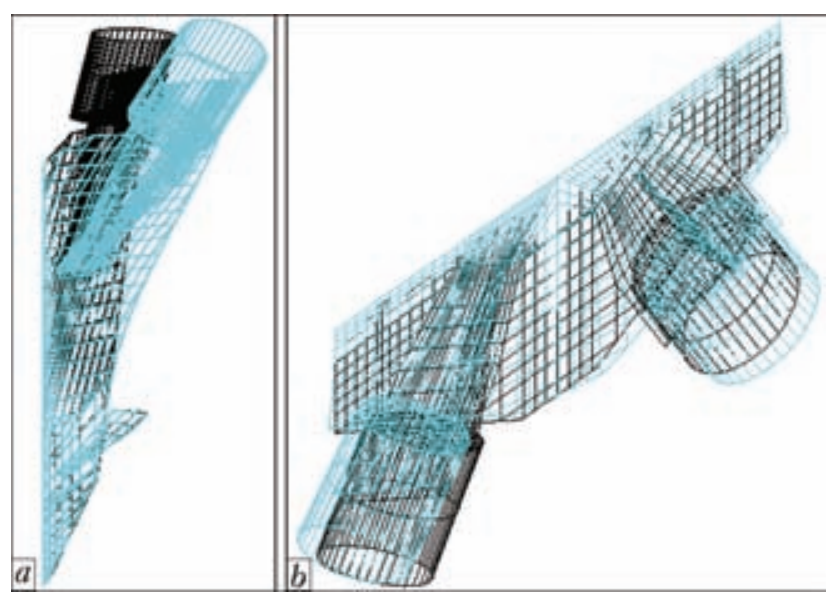

Figure 17. Schematics of supporting gusset deformation: $a$ - lower; $b$ - upper gussets 


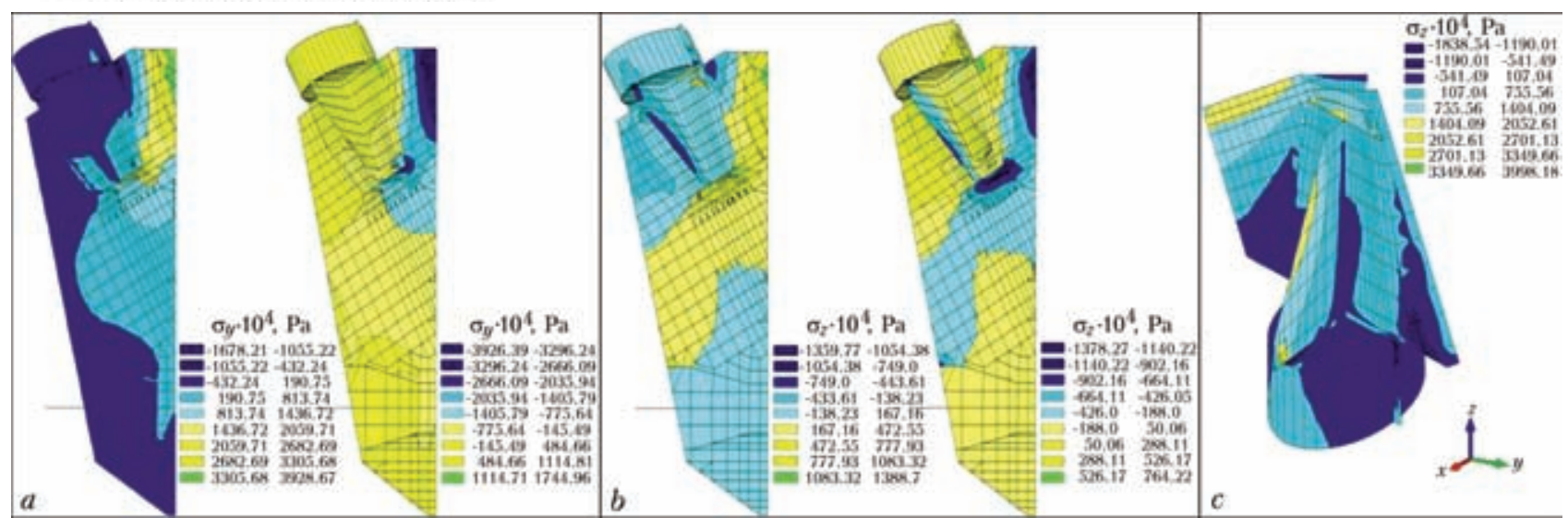

Figure 18. Isofields of stresses on faces of lower $(a, b)$ and upper $(c)$ supporting nodes

teristic forms of brace vibrations and respective magnitudes of natural vibration periods are given in Figure 13, $b$.

To determine the critical velocity of wind flow $v_{\text {cr }}$, capable of causing wind resonance in the brace, we will use formulas given in [5]. In the first approximation we will assume that critical wind velocity, caused by resonance vibrations in the direction normal to wind flow, is equal to

$$
v_{\mathrm{cr}}=\frac{d}{T_{i} \mathrm{Sh}}=\frac{0.194}{0.084 \cdot 0.2}=11.6 \mathrm{~m} / \mathrm{s} \approx 12 \mathrm{~m} / \mathrm{s},
$$

where $T_{i}=0.082 \mathrm{~s}$ is the period of brace natural vibrations by $i$-th form; $\mathrm{Sh}=0.2$ is the Strouhal number for round section; $d=0.194 \mathrm{~m}$ is the diameter of tie element $(193.7 \times 6 \mathrm{~mm}$ pipe $)$ in three upper levels of the tower.

Using the value of critical velocity $v_{\mathrm{cr}}=$ $=12 \mathrm{~m} / \mathrm{s}$ of wind flow as initial data, the aerodynamic model (Figure 14) was applied to determine the nature of distribution of wind flow and pressure over the surface of NVP structural elements.

Performed calculations showed that structural elements of NVP tower and flue affect the parameters of wind flow distribution around the

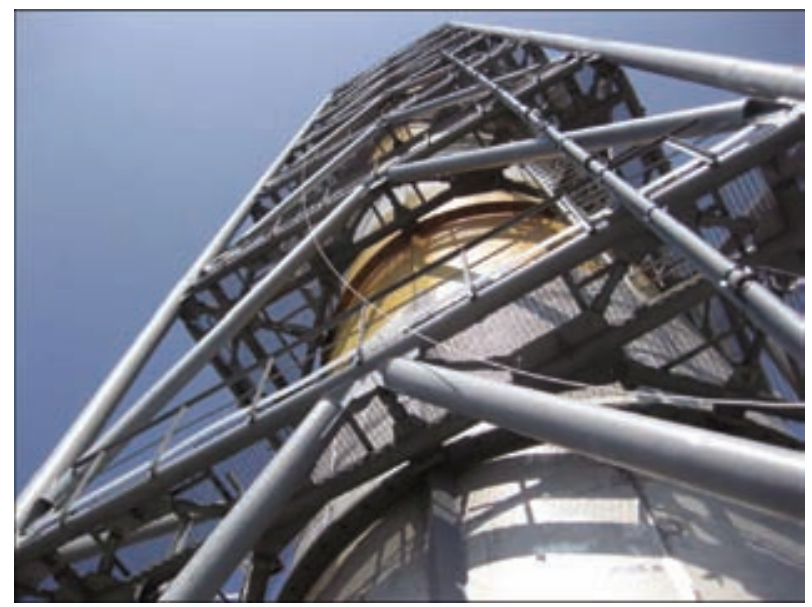

Figure 19. General view of NVP tower structure tower flue and elements of vertical ties. Increase of wind flow velocity along the flue side surface (Figure 15) leads to the braces located in this zone becoming exposed to higher magnitudes of wind pressure (Figure 16).

In addition, cross-effect of structural elements of NVP tower leads to the fact that wakes arising behind the braces (vertical ties) penetrate into the wake jets of flows formed by tower corner posts. As a result the wakes of vertical ties are subjected to turbulization practically immediately after the flow separation, and a turbulent wake forms between layers located at a certain distance from each other with a shift.

Studies [1, 6] note that the most hazardous are vibrations of a non-insulated cylinder, i.e. cylinder located in the wake jet of another one or in parallel to other cylinders. Here brace vibration arises much easier - at lower velocity of the flow and can be maintained in a wide range of velocities, and not in a certain range, that is why it is more dangerous. According to [1], aerodynamic forces applied to the construction vary by the harmonic law. In this connection, harmonic analysis of the structure was performed in order to determine the extent of wind flow influence on strength properties of support elements of vertical ties.

Results, derived at solving the aerodynamic problem, were used as initial data at determination of the magnitude of disturbing force (intensity amplitude), applied to vertical tie elements.

As a result of calculation of a precised model of harmonic force action (intensity amplitude $F_{0}$ ) simulating the dynamic impact of wind load, values of stresses and strains were determined in supporting gussets and other structural elements of the considered fragment of the construction.

Analysis of the derived results showed that the applied forces cause out-of-plane deflection of supporting gussets. Figure 17 gives the deformation diagrams of supporting gussets. 
Bending of lower supporting gussets leads to formation on their faces of stresses reaching values $\sigma_{y}= \pm 38.56 \mathrm{MPa}$. Regions of highest stresses are located in upper zone of supporting gussets, in the area of their abutment to tower posts. In addition stress increase is observed in areas of variable rigidity, namely in zones of connection of supporting gussets to brace gussets. Isofields of stresses $\sigma_{y}$ and $\sigma_{z}$ in supporting nodes are given in Figure 18.

A zone with a pronounced stress raiser is found in the brace upper node, in the area of stiffener abutment to end plug. Schematic of deformation and isofields of stresses $\sigma_{z}$ on the faces in the zone of upper supporting node are given in $\mathrm{Fi}$ gure 18, $c$. In these sections stresses reach the magnitudes of $\sigma_{z}=39.9 \mathrm{MPa}$.

Additional investigations and calculations. Additional investigations revealed the following facts.

1. Considering that coefficient of transverse force $C_{y}$, used at determination of disturbing force, is the theoretically minimum possible value and reaches greater values in practice, calculation of precised model for $C_{y}=0.3$ was performed.

Performed calculations showed that the nature of stress distribution in structural elements remained similar to earlier obtained analogous isofields. Here stress values on face surfaces of lower supporting gussets increased by $25 \%$ (up to $49 \mathrm{MPa}$ ). Increase of stress values was also noted in the upper supporting node.

2. Design solutions of supporting nodes are identical in all the sections of NVP tower, therefore evaluation check of supporting nodes of lower lying sections was performed.

Calculations showed that for vertical ties made of round $219 \times 6 \mathrm{~mm}$ pipe, the period of the first form of natural vibrations $T_{i}=0.07 \mathrm{~s}$, and critical velocity $v_{\text {cr }}=15.5-16.0 \mathrm{~m} / \mathrm{s}$. Stress amplitude modulo in supporting gussets, depending on the value of dynamic coefficient $C_{y}$, can change from 31 to $39 \mathrm{MPa}$.

For vertical tie elements made of round $245 \times$ $\times 8 \mathrm{~mm}$ pipe, $T_{i}=0.06 \mathrm{~s}, v_{\text {cr }}=20.5-21.0 \mathrm{~m} / \mathrm{s}$.

Obtained values of critical velocities of wind flow are not mentioned in statistical data on wind velocities recorded in Chernobyl weather station over the elapsed period. The provided information on wind velocities was given as hourly measurements that introduces a certain averaging parameter. In [7] it is noted that the mean velocity of wind averaging depends on averaging time. At shortening of averaging interval maximum value of mean velocity, corresponding to this interval, becomes higher. For instance, the difference between the mean hourly velocity and mean veloc- ity over $20 \mathrm{~s}$ period can differ two times. Thus, for sections of the third-fourth level, the wind flow velocity $v=15-16 \mathrm{~m} / \mathrm{s}$ is probable.

3. Considering that the Strouhal number is of a tentative nature and can vary for different crosssectional shapes within a certain range (for cylinders it is assumed that $\mathrm{Sh}=0.2$, although in practice $\mathrm{Sh}=0.185-0.220$ ), external loads can change their values in an even greater range that, in its turn, leads to an even greater increase of stresses in supporting elements of NVP tower frame.

\section{Analysis of stresses in slotted gusset induced} by resonance vibration of braces. Calculated values of cyclic stresses arising in a slotted gusset at the boundary of a fillet weld connecting the gusset to post pipe are considered for compliance to norms in force in Ukraine [8], and IIW Recommendations [9].

According to [8], fatigue limit $R_{\rho}$ for 5 th group of elements, into which the connection of a slotted gusset to the post can be included, $R_{\sigma_{-1}}=16.83 \mathrm{MPa}$ at residual stresses of not more than $0.5 \sigma_{\mathrm{y}}$ in the cracking zone for a symmetrical loading cycle. Note that according to norms [8], fatigue limit is determined on the base of $10^{7}$ loading cycles.

As in the gusset cyclic stresses under the conditions of resonance vibrations of the brace are equal to $\pm 39 \mathrm{MPa}$, crack initiation can be anticipated at fatigue life of $8.04 \cdot 10^{5}$ loading cycles. Allowing for brace vibration frequency under resonance conditions $(12.2 \mathrm{~Hz}), 20 \mathrm{~h}$ of operation are sufficient for fatigue cracks to form.

According to IIW procedure, limit values of stress ranges on the base of $2 \cdot 10^{6}$ loading cycles are given for characteristic types of welded connections. For a connection close to the one found in NVP tower, limit value of stress range is $45 \mathrm{MPa}$.

As in the gusset stress range value is equal to $78 \mathrm{MPa}$, fatigue life, at which fatigue cracks can be anticipated, is equal to $384 \cdot 10^{3}$ loading cycles, according to this procedure.

The given data once more confirm the fatigue nature of crack initiation in NVP tower nodes.

Analyzing the causes for crack initiation in the nodes of NVP tower, we cannot avoid assessment of the taken design solutions. The load-carrying frame of NVP tower is made of cylindrical pipes (Figure 19).

Selection of this type of pipe sections for tower structural elements is quite justified, as it allows lowering wind loads on the construction, increasing design length of elements, and, therefore, reducing construction weight and its cost. In addition, tubular elements have an increased cor- 


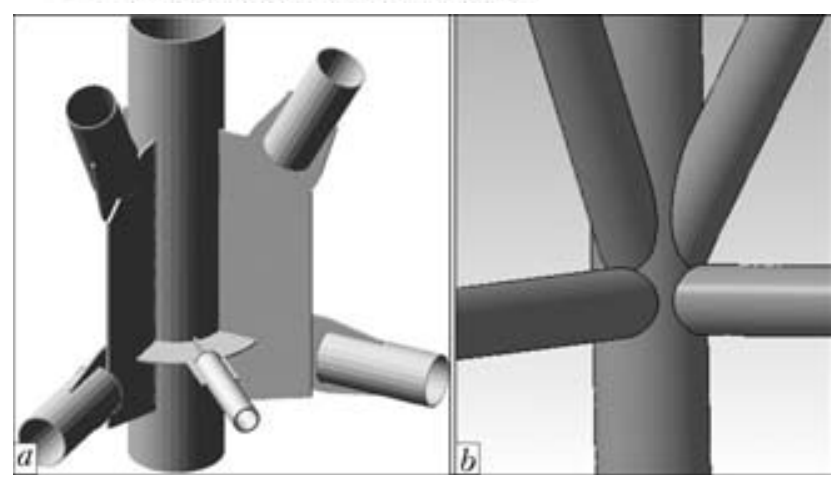

Figure 20. Schematics of node connection of NVP tower structural elements with the post: $a$ - with slotted gussets; $b$ - with direct abutment

rosion resistance owing to good air blowing and small surface area. These advantages, however, can be realized in full only at a rational design of node connections. It is known that in tubular structures node connections in a number of cases predetermine the strength and reliability of the entire construction [10].

Over the recent decades, in connection with application of cylindrical pipes as load-carrying elements of stationary off-shore platforms and other critical constructions, a large volume of investigations has been performed, which are aimed at development of optimum node design solutions, and methods of assessment of their strength under static and cyclic loading. It is shown that the most rational solution is direct abutment of lattice elements to the post. The structure has a high strength, low stress concentration, small number of welded connections, and high corrosion resistance. For such nodes normative documents for their strength analysis [11, 12 , etc.] at static and cyclic loading have been developed. For comparison let us give the node of NVP tower and a node, corresponding to modern concepts of tubular structure design ( $\mathrm{Fi}^{-}$ gure 20). If the design of NVP tower was made on an up-to-date level, many drawbacks could have been avoided.

\section{Conclusions}

1. Cracks in ChNPP NVP tower nodes are of a systematic nature. They formed in the zones of node welded connections of tower three upper tiers with lattice elements from $193.7 \times 6 \mathrm{~mm}$ pipes. Cracks were detected in 17 nodes of post slotted gusset and in 17 nodes of brace attachment to straining sill.

2. There is no doubt that cracking is caused by cyclic forces acting in braces. This is confirmed by characteristic locations of their formation and presence of cracks from both ends of braces.
3. Cracks are of fatigue origin, initiate in post gussets on the outer surface from two sides, and propagate along the weld boundary from gusset upper edge and in-depth. Fractographic studies of fracture surfaces revealed initiation sites, characteristic relief of fatigue fracture and traces of fatigue crack arresting. In sill nodes the cracks also have characteristic features of fatigue fracture.

4. Aerodynamic and strength analyses of the construction and its individual elements have convincingly demonstrated that cracking is caused by resonance vibrations of braces in the tower three upper sections, directed out of face plane and inducing alternating bending stresses in the nodes. Vibration frequencies and forces transferred to nodes have been determined.

5 . Fields of stresses caused by periodic forces in the braces confirm the presence of a zone of fatigue fracture initiation and propagation, and maximum stress levels greatly exceed welded connection fatigue limits.

6. Calculation showed that braces made from $219 \times 6 \mathrm{~mm}$ pipes present a hazard in terms of fatigue crack initiation. This should be taken into account in development of NVP tower repair project.

7. The tower was designed using out-dated node design solutions, characterized by numerous zones of high stress concentration, low fatigue and corrosion resistance.

1. Savitsky, G.A. (1972) Wind loading on constructions. Moscow: Strojizdat.

2. (2012) Results of inspection of welded joints of new ventilation pipe frame on «Chernobyl NPP» object: Report. Kiev: PWI.

3. (2012) Expertise of causes of crack-type defect initiation in new ventilation pipe: Report. Kiev: UkrAtomenergo.

4. Maclean, D., Campbell, R., Colwell, R. (2012) Independent examination of structural defects of NVP: Sci.-Techn. Report. Kiev.

5. (1978) Guidelines on design of buildings and constructions under wind action. Moscow: Strojizdat.

6. Vilkerd, D.S., Popov, S.G., Savitsky, G.A. (1951) Oscillations of bodies in aerodynamic wake. Vestnik $M G U, 12,23-25$

7. Simiu, E., Scanlan, R.H. (1984) Wind effects on buildings and constructions. Moscow: Strojizdat.

8. $D B N$ V.2.6-163:2010: Steel structures. Norms of design, fabrication and assembly. Valid from 01.12.11. Kiev: Minregionbud.

9. Recommendations for fatigue design of welded joints and components. IIW Doc. XIII-1539-96.

10. Marshal, P.W. (1984) Connections for welded tubular structures. In: Proc. of Int. Conf. on Welding of Tubular Structures. Pergamon Press, 11-17.

11. VSN 51.4-85: Departmental building norms. Gussetless connections of structures of offshore oilfield facilities. Procedure of strength analysis. Introd. 03.06.1985. Moscow: Mingazprom.

12. API Recommended practice for planning, designing and constructing fixed offshore platforms: Doc. RP2A.

Received 03.09.2013 